\title{
Chronic agmatine treatment modulates behavioral deficits induced by chronic unpredictable stress in wistar rats
}

\author{
Hira Rafi ${ }^{1, *}$, Hamna Rafiq ${ }^{2}$, Iqra Hanif ${ }^{3}$, Rafia Rizwan $^{4}$, Muhammad Farhan ${ }^{5}$ \\ Neurochemistry and Biochemical Neuropharmacology Research Unit, Dept. of Biochemistry, University of Karachi, Karachi, \\ Pakistan
}

*Corresponding Author:

Email: hira.rafi@hotmail.com

\begin{abstract}
Aim: Stressful life events modifies brain neuronal structure that impairs normal brain functions and leads to behavioral deficiencies. Agmatine is a well-recognized neurotransmitter and has been reported to be released as a response to several stressful stimuli. Chronic mild stress model induces depressive like behaviors in rats which simulates human depression.

Material and Method: 36 Albino Wistar rats were equally divided in controls and CMS exposed groups that further divided into three groups $(\mathrm{n}=6)$. Agmatine $(100 \mathrm{mg} / \mathrm{Kg} /$ day $)$ and mirtazapine $(30 \mathrm{mg} / \mathrm{Kg} /$ day $)$ were administered to respective animals while controls with $0.9 \%$ saline orally. Test rats were exposed to CMS after one hour of drugs administration and behaviors were observed in different paradigms post 24 hours of drugs monitoring for 28 days.

Results: Agmatine significantly increased the time spent and entries of stressed rats in light/ dark transition box test and elevated plus maze test while struggling and mobility in forced swim test was also improved in rats treated with agmatine.

Conclusion: All the data collected and results obtained clearly validated the antidepressant and anxiolytic activities of agmatine in CMS induced depression in rats. Thus, drug development based on brain agmatine levels may leads to novel approach for stress related mood disorders therapeutics.
\end{abstract}

Keywords: Chronic mild stress; Agmatine; Mirtazapine; Antidepressant; Behaviors.

\section{Introduction}

Persistent stressful life events may result in anxiety and depression and other psychiatric illnesses (Miller D et al., 2002, Stetler C et al., 2011). Constant recurring of stress in humans may leads to depression in vulnerable individuals (De Kloet E et al., 2005, Siegrist J 2008). Peripheral and interior stress factors for example exposure to traumatized events and prolonged inflammation that may cause oxidative and nitrosative stress pathways that causes depression in a person (Maes et al., 1995, 2008, 2012). Effects on neuroendocrine responses may also observed in individuals exposed to constant stress (Mattews $\mathrm{K}$ et al., 2001). Willner et al in 1987 (Willner et al., 1987) developed an animal model of unpredictable chronic mild stress (UCMS) that interconnects chronic stressors and depression. Rodents are constantly introduced to mild unpredictable stresses such as deprivation of food or water, restraint or temperature fluctuation. More commonly after 14 days for UCMS treatment, animals grow various signs of depression similar to humans for instance loss of weight, sleep deprivation and anhedonia (Willner P et al., 1987, 1991, 1992, 2005). A number of antidepressants revealed efficiency in UCMS (Willner Pet al., 1987, Monleon et al., 1995).

Agmatine (4-Aminobutyl) guanidine) also called decarboxylated arginine is a metabolite located endogenously among metabolism of polyamine, production of nitric oxide and urea cycle pathway (Reis and regunathan, 2000). Agmatine described as a neuromodulator in CNS, since it:

i) Is produced in a $\mathrm{Ca}^{2+}$ way from synaptosomes (Sastre et al., 1997),

ii) Is deactivated by selective reuptake ( Sastre et al., 1997),

iii) Is deposited in billions of neurons with selectivity in the brain (Otake et al., 1998),

iv) Is degraded enzymatically in synaptosomes by agmatinase (Tabor and Tabor, 1984),

v) Has a number of molecular targets such as I1R, and $\alpha 2$-adrenergic receptors, $5 \mathrm{HT}_{3}$ receptors, antagonized membrane $\mathrm{Ca}^{+2}$ channels and isoforms of NOS (nitric oxide synathase) and blocks NMDA receptors inside brain (Reis and Regaunathan, 1998, 1999, 2000).

Additionally, agmatine has been evolving as a reputed unconventional therapeutic implements that could assist traditional pharmacotherapy of depression. It has been observed that agmatine exhibited an antidepressant like outcomes in tail suspension test (TST) and forced swim test (FST), which was coordinated by modulation of NMDA receptors, opioids and monoaminergic systems and pathway of L-arginine nitric oxide (Zomkowski et al., 2002, 2004, 2005). Notably, 
Shopsin (2013) recently described a clinical antidepressants therapeutics of agmatine in subjects effected by depression.

Mirtazapine

2-Methyl-1,2,3,4,10,14b-

hexahydrobenzo[c] pyrazino[1,2-a] pyrido[3,2-f] azepine used as an antidepressant in humans (Berton and Nestler, 2006). A convincible mechanism of antidepressant action of mirtazapine is blockade of 2adrenergic presynaptic receptors (Rauggi et al., 2005). In vivo, various studies determine the interconnection of 5 HT subtype receptors and mirtazapine and mediated behaviors (Dazzi L et al., 2008).

The present study was conducted to investigate the anxiolytic and antidepressant role of agmatine, whether it modulates the behavioral inadequacies affected by chronic unpredictable mild stress rat model induced despair and fear and comparison of agmatine with classical antidepressant mirtazapine.

\section{Materials and Methods \\ Animals}

Male Albino wistar rats, approximately 6-8 months old and weighing between (120-180 gm) were purchased from Dow University of health and sciences, Karachi. All the animals used in this experiment were treated accordance to the protocols specified by institutional ethics and care committee. All animals were housed separately under controlled conditions of
12:12 hrs. light /dark cycle, temperature $25 \pm 1^{\circ} \mathrm{C}$ and free accesses to water and food for 3 days for acclimatization before the experiments.

\section{Drugs and administration}

Agmatine and mirtazapine were obtained from Sigma chemicals, Co. St. Louis. USA and were administered orally by stainless steel oral gavage. The selected dose of Agmatine was $(100 \mathrm{mg} / \mathrm{Kg})$ and mirtazapine was $(30 \mathrm{mg} / \mathrm{Kg})$ per day. Both drugs were dissolved in distilled water at the ratio of $1: 1 \mathrm{w} / \mathrm{v}$. Control groups received $0.9 \%$ saline.

\section{Experimental protocol}

36 rats were divided randomly into controlunstressed and test-UCMS groups (each group $=18$ rats) and daily administered with saline and drugs 01 hour before stresses and behavioral tests in various paradigms for 28 days. Both groups were further divided into 3 groups (each group $=6$ rats)

a) Group I: treated with saline and labeled as control groups.

b) Group II: not exposed to stresses in control group but treated with UCMS stressors in tests and both were administered with agmatine $(100 \mathrm{mg} / \mathrm{Kg})$ orally.

c) Groups III: the division was similar to group II but treated with mirtazapine $(30 \mathrm{mg} / \mathrm{Kg})$ orally.

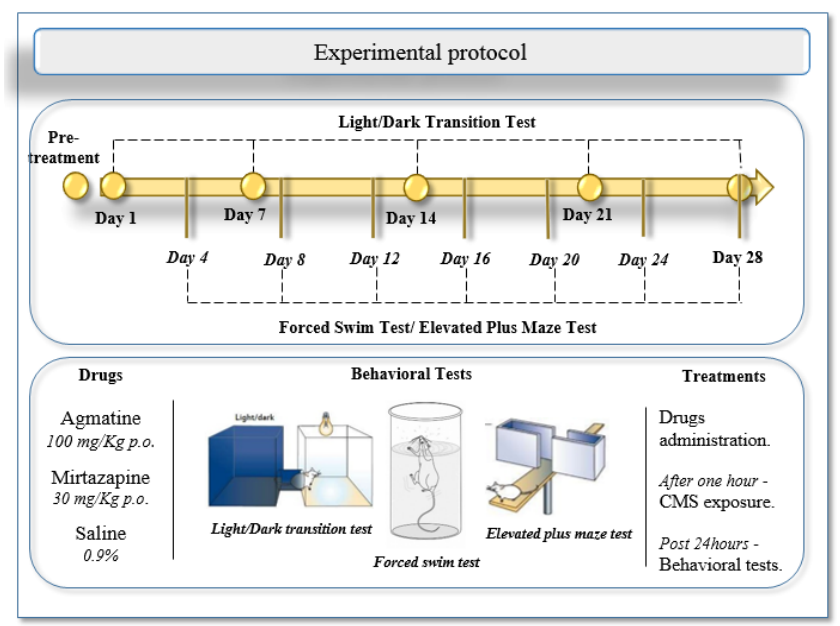

Fig. 1: Schematic representation of experimental protocol and treatments and behavioural evaluations

\section{Elevated Plus-Maze Test (EPM)}

Elevated plus maze has been commonly endorsed to observe anxiety in rats (Pellow et al., 1985). The apparatus consists of plus shaped four arms in which two arms are open $(50 \times 10 \mathrm{~cm})$ and two closed arms $(50 \times 20 \mathrm{~cm})$ with $15 \mathrm{~cm}$ high opaque walls. Open arms edges were $.25 \mathrm{~cm}$ high to avoid fall of rat. The maze was elevated $100 \mathrm{~cm}$ above the ground. Each rat is positioned at the center of maze facing enclosed arm. Time spent and entries in open arms were observed in 5 minutes test period (Pellow and file, 1986).

\section{Light Dark Box Testing}

Light dark transition test is renowned for analyzing anxiety in rodents. The apparatus consists of two chambers of equal size made up of transparent and black opaque Plexiglas $(20 \times 30 \times 30 \mathrm{~cm})$. the partition is dividing the compartment has a $10 \times 10 \mathrm{~cm}$ door in the middle of wall through which rat can move from one chamber to another. Single animal was placed in the middle of light chamber facing the opposite side from the middle wall opening. Behaviors measured were entries and time spent in light box for 05 minutes. 


\section{The Forced Swim Testing}

Forced swim test is known as an authentic test for examine depression-like behavior. The apparatus was a transparent glass cylinder $(12 \mathrm{~cm}$ diameter and $22 \mathrm{~cm}$ height). The cylinder was filled up to $10 \mathrm{~cm}$ with water $\left(25^{\circ} \mathrm{C}\right)$. Each rat was placed into the apparatus and struggling of rat was monitored for 5 minutes. The cylinder was filled with clean water after each test.

\section{Statistics}

All the data obtained are exhibiting as mean \pm SD (standard deviation) and evaluated as three way ANOVA repeated measured designs SPSS version 17, followed by Newman Keul's post hoc determination. Significance was considered when $\mathrm{P}$ value was $<0.05$.

\section{Results \\ Anxiolytic and Antidepressant Responses of Agmatine and Mirtazapine in Light Dark Transition Test (Entries in Lit Area).}

The reversal effects of agmatine and mirtazapine on unpredictable chronic mild stress induced depression in unstressed and stress rats are determined by frequency of entries in lit box of light/dark transition paradigm in figure 01 . The results obtained were analyzed by III way ANOVA repeated measures design which demonstrated the effects of days $(F(4,33)=$ 3.214) were non-significant however, significant effects of drug $(\mathrm{F}(1,33)=367.546 \mathrm{p}<0.05)$, stress $(\mathrm{F}(1,33)=$ $66.124 \mathrm{p}<0.10)$, and interaction of drugs days and stress $(\mathrm{F}(4,33)=15.882 \mathrm{p}<0.01)$ were attained.

\section{Table 1}

\begin{tabular}{|c|l|l|c|}
\hline Week & \multicolumn{1}{|c|}{ Day } & \multicolumn{1}{|c|}{ Streasors } & Duration \\
\hline 1. & Monday & Inversion of Light/Dark Cycle + Overcrowding & 1 hour \\
\hline & Tuesday & Wet Bedding + Cold Stress 4 ${ }^{\circ}$ C & 1 hour \\
\hline & Wednesday & Cage Tilting + Bed Chipping Removed & 24 hours \\
\hline & Thrusday & Soil Bedding +Water Deprivation & 24 hours \\
\hline & Friday & Restraint Stress + Cage Shaking (200 Rpm) & 2 hours \\
\hline & Saturday & Overnight Illumination + Food Deprivation & 24 hours \\
\hline & Sunday & White Noise +Stroboscopic Light & 3 hours \\
\hline & Monday & Wet Bedding + Cold Stress 4 ${ }^{\circ}$ C & 1 hour \\
\hline & Tuesday & Cage Tilting + Bed Chipping Removed & 24 hours \\
\hline & Wednesday & Soil Bedding +Water Deprivation & 24 hours \\
\hline & Thrusday & Inversion of Light/Dark Cycle + Overcrowding & 1 hour \\
\hline & Friday & White Noise +Stroboscopic Light & 3 hours \\
\hline & Saturday & Restraint Stress + Cage Shaking (200 Rpm) & 2 hours \\
\hline & Sunday & Overnight Illumination + Food Deprivation & 24 hours \\
\hline 3. & Monday & Cage Tilting + Bed Chipping Removed & 24 hours \\
\hline & Tuesday & Restraint Stress + Cage Shaking (200 Rpm) & 2 hours \\
\hline & Wednesday & Soil Bedding + Water Deprivation & 24 hours \\
\hline & Thrusday & Wet Bedding + Cold Stress 4 ${ }^{\circ}$ C & 1 hour \\
\hline & Friday & White Noise +Stroboscopic Light & 3 hours \\
\hline & Saturday & Inversion of Light/Dark Cycle + Overcrowding & 1 hour \\
\hline & Sunday & Cage Tilting + Bed Chipping Removed & 24 hours \\
\hline 4. & Monday & Restraint Stress + Cage Shaking (200 Rpm) & 2 hours \\
\hline & Tuesday & Overnight Illumination + Food Deprivation & 24 hours \\
\hline & Wednesday & Inversion of Light/Dark Cycle + Overcrowding & 1 hour \\
\hline & Thrusday & White Noise +Stroboscopic Light & 3 hours \\
\hline & Friday & Soil Bedding + Water Deprivation & 24 hours \\
\hline & Saturday & Wet Bedding + Cold Stress 4 ${ }^{\circ} \mathrm{C}$ & 1 hour \\
\hline & Sunday & Overnight Illumination + Food Deprivation & 24 hours \\
\hline & & & \\
\hline
\end{tabular}

Post-hoc analysis by Newman Keul's tests explained that agmatine after $7^{\text {th }}(\mathrm{p}<0.05)$ and $14^{\text {th }}, 21^{\text {st }}$, $28^{\text {th }}(\mathrm{p}<0.01)$ administration in unstressed and after $14^{\text {th }}$, $28^{\text {th }}(\mathrm{p}<0.01)$ and $21^{\text {st }}(\mathrm{p}<0.05)$ treatment in stressed rats increased entries in lit area significantly whereas, mirtazapine increased entries in bright area after $7^{\text {th }}$, $14^{\text {th }}, 21^{\text {st }}$ and $28^{\text {th }}(\mathrm{p}<0.01)$ in unstressed and stress exposed rats when both drugs were compared to saline controls on same day of drug administration. Further comparing drugs to their first treatment, agmatine improved the number of entries in lit compartment after $14^{\text {th }}, 28^{\text {th }}(\mathrm{p}<0.05)$ and $21^{\text {st }}(\mathrm{p}<0.01)$ in unstressed rats and $14^{\text {th }}, 21^{\text {st }}$ and $28^{\text {th }}(\mathrm{p}<0.01)$ administration in stressed rats 24 hours later and mirtazapine after $14^{\text {th }}$, $21^{\text {st }}$ and $28^{\text {th }} \quad(\mathrm{p}<0.01)$ treatment in stressed and unstressed animals individually. Stress significantly decreased frequency of rats arrival in bright box in saline group after $28^{\text {th }}(\mathrm{p}<0.05)$, agmatine after $7^{\text {th }}$ 
$(\mathrm{p}<0.01)$ and animals treated with mirtazapine after $21^{\text {st }} \quad(\mathrm{p}<0.05)$ day of administration.
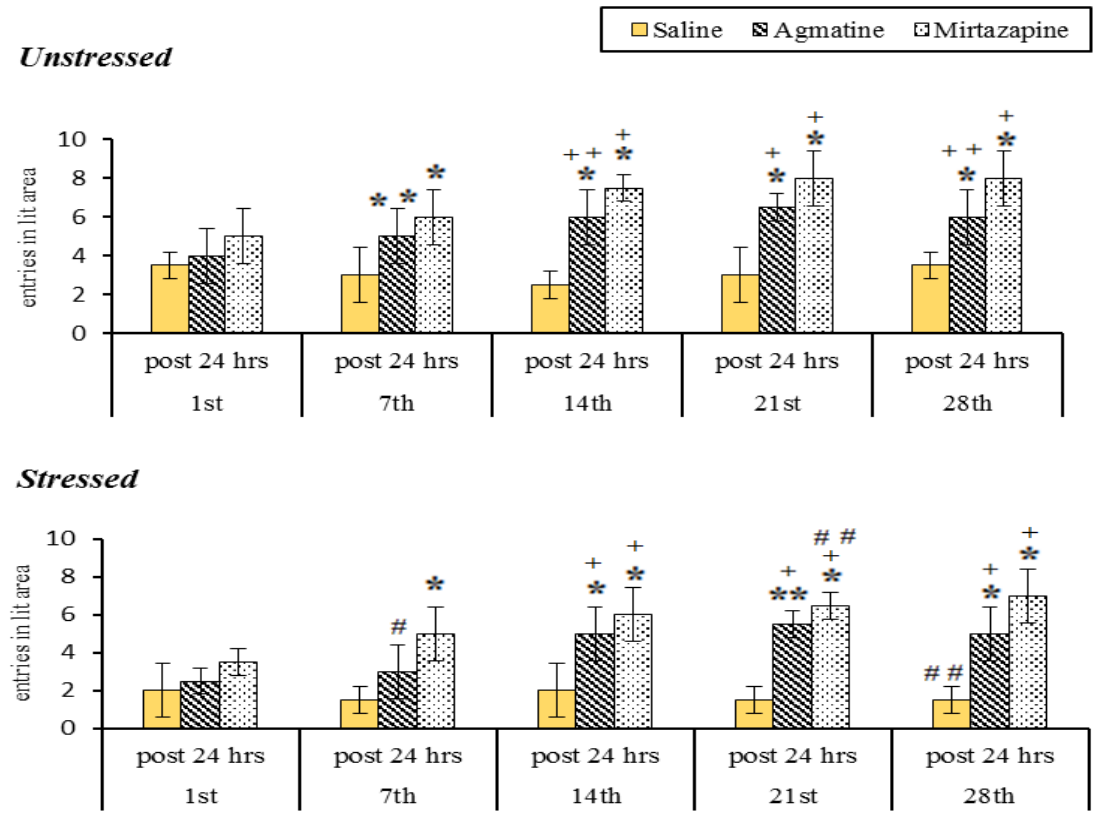

Fig. 2: Anxiolytic and Antidepressant Responses of Agmatine and Mirtazapine in Light Dark Transition Test (Entries in Lit Area)

Values are means \pm SD $(n=6)$ as administered post 24 hours of drug administration. Significant differences by Newman-Keul's test: groups that differ significantly from respective saline treated controls $* \mathrm{p}<0.01$, $* * p<0.05 ;+$ similar drug treated groups that significantly differ from $1^{\text {st }}$ administration $\mathrm{p}<0.01$; $\# \mathrm{p}<0.01$, \#\#p<0.05 from similarly administered drug of unstressed to stressed group on same day following three way ANOVA (repeated measure design)

Anxiolytic and Antidepressant Responses of Agmatine and Mirtazapine in Light dark transition test (time spent in lit area)

Assessments of time spent in light box of light dark transition tests by repeated administration of agmatine and mirtazapine in unstressed and stressed rats are explained in Fig. 2. Observed results were analyzed by III way ANOVA (repeated measure design) that described the effects of days $(F(4,33)=15.891$ $\mathrm{p}<0.01)$, drugs $(\mathrm{F}(1,33)=175.658 \mathrm{p}<0.10)$ and interaction between days, drug and stress $(F(4,33)=$ $193.9 \mathrm{p}<0.01)$ were significantly obtained however, effects of stress $(F(1,33)=43.969)$ were nonsignificant.

Post-hoc analysis by Newman Keul's test explained that agmatine after $7^{\text {th }}(\mathrm{p}<0.05)$ and $14^{\text {th }}, 21^{\text {st }}$, $28^{\text {th }}(\mathrm{p}<0.01)$ administration and mirtazapine post 24 hours of $1^{\text {st }}(\mathrm{p}<0.05)$ and $7^{\text {th }}, 14^{\text {th }}, 21^{\text {st }}, 28^{\text {th }}(\mathrm{p}<0.01)$ treatment significantly increased the time spent of unstressed rats in light box whereas, a day later of agmatine $28^{\text {th }}(\mathrm{p}<0.01)$ administration and mirtazapine after $14^{\text {th }}, 21^{\text {st }}$ and $28^{\text {th }}(\mathrm{p}<0.01)$ day of treatment significantly improved the duration spent in stress exposed rats when both drugs were compared with saline controls. Additionally, after $14^{\text {th }}(\mathrm{p}<0.01)$ day of saline administration, controls exhibited significant increased time spent in unstressed rats. However, agmatine after $28^{\text {th }}(\mathrm{p}<0.05)$ in stress affected rats and mirtazapine after $28^{\text {th }}(\mathrm{p}<0.01)$ treatment in both unstressed and stressed groups increased the length of time spent in lit compartment when all the drugs were compared from their first administration. Stress caused reduction in time that spent in lit box observed after first treatment of mirtazapine ( $\mathrm{p}<0.01)$ significantly.

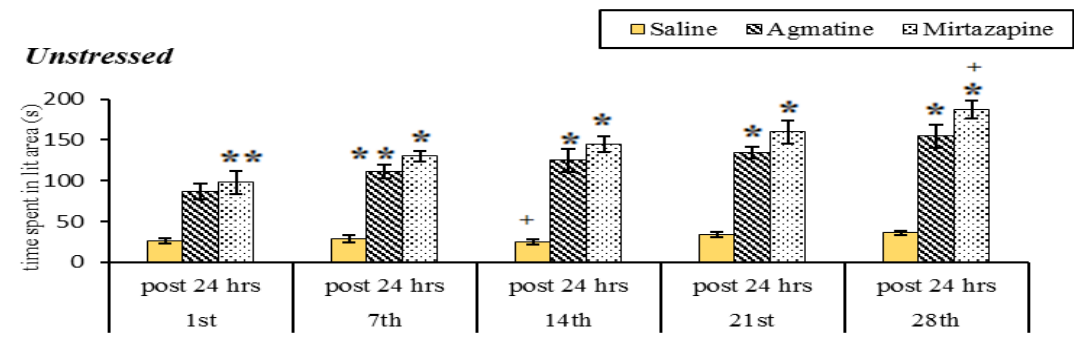




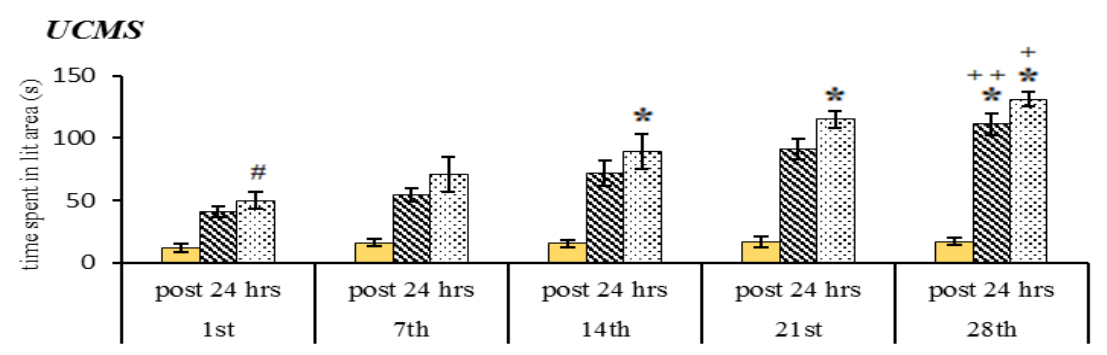

Fig. 3: Anxiolytic and Antidepressant Responses of Agmatine and Mirtazapine in Light dark transition test (time spent in lit area)

Values are means $+\mathrm{SD}(\mathrm{n}=6)$ as administered post 24 hours of drug administration. Significant differences by Newman-Keul's test: groups that differ significantly from respective saline treated controls $* \mathrm{p}<0.01$, $* * \mathrm{p}<0.05$; similar drug treated groups that significantly differ from $1^{\text {st }}$ administration $+\mathrm{p}<0.01,++\mathrm{p}<0.05$;

$\# \mathrm{p}<0.01$ from similarly administered drug of unstressed to stressed group on same day following three way ANOVA (repeated measure design).

Antidepressant like activity of Agmatine and Mirtazapine in Forced swim Test (struggling time)

The effects of chronic mild stress and its attenuation by agmatine and mirtazapine are explained in figure 03 in forced swim test experiment. The results were analyzed by III way ANOVA (repeated measure design) which determined the effects of days $(\mathrm{F}(6,33)$ $=0.347)$ to be non-significant whereas, drugs $(\mathrm{F}(1,33)$ $=218.644 \mathrm{p}<0.10)$, stress $(\mathrm{F}(1,33)=68.134 \mathrm{p}<0.10)$ and interactive effects of days, drugs and stress (F (6, $33)=51.857 \mathrm{p}<0.01)$ affected significantly. Post-hoc analysis by Newman Keul's test demonstrated that agmatine increased the struggling of unstressed rats after $1^{\text {st }}, 4^{\text {th }}, 6^{\text {th }}, 7^{\text {th }}(\mathrm{p}<0.01)$ administration and $5^{\text {th }}, 6^{\text {th }}$ and $7^{\text {th }}(\mathrm{p}<0.01)$ treatment in stressed group of rats while mirtazapine improved struggling $4^{\text {th }}, 5^{\text {th }}, 6^{\text {th }}$ and $7^{\text {th }}(\mathrm{p}<0.01)$ in unstressed and $4^{\text {th }}, 5^{\text {th }}(\mathrm{p}<0.05)$ and $6^{\text {th }}$, $7^{\text {th }}(\mathrm{p}<0.01)$ post 24 hours of administration in UCMS exposed rats while both drugs were compared with saline controls. Agmatine after $6^{\text {th }}$ and $7^{\text {th }}(\mathrm{p}<0.01)$ management in unstressed controls and mirtazapine after $5^{\text {th }}, 6^{\text {th }}, 7^{\text {th }}(\mathrm{p}<0.0)$ in unstressed and $6^{\text {th }}(\mathrm{p}<0.05)$ and $7^{\text {th }}(\mathrm{p}<0.01)$ treatment in stressed rats exhibited greater struggling from their first drug administration individually. Agmatine significantly produced antidepressant like activity after $4^{\text {th }}(\mathrm{p}<0.01)$ and mirtazapine after $5^{\text {th }}(\mathrm{p}<0.05)$ and $6^{\text {th }}, 7^{\text {th }}(\mathrm{p}<0.01)$ administration in stressed rats.

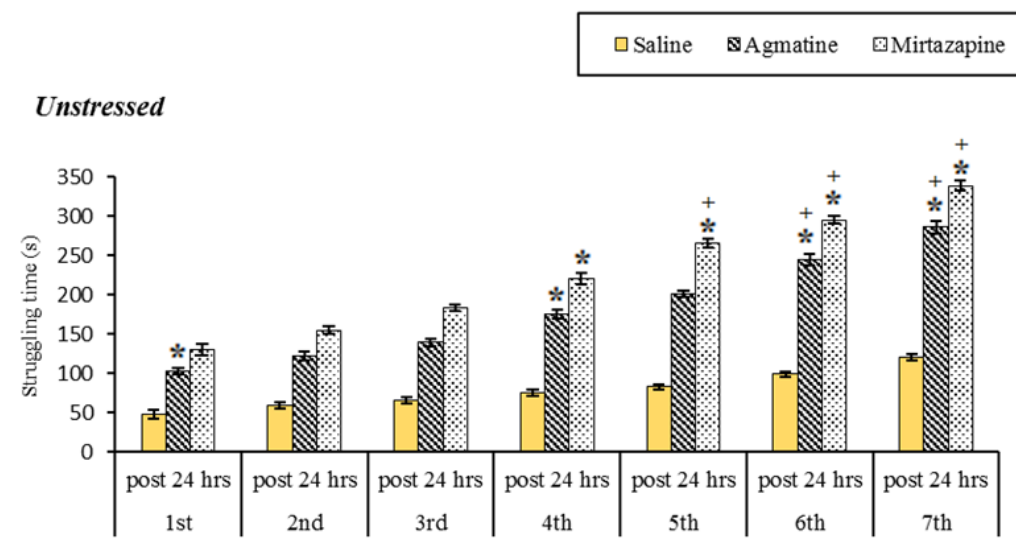

UCMS

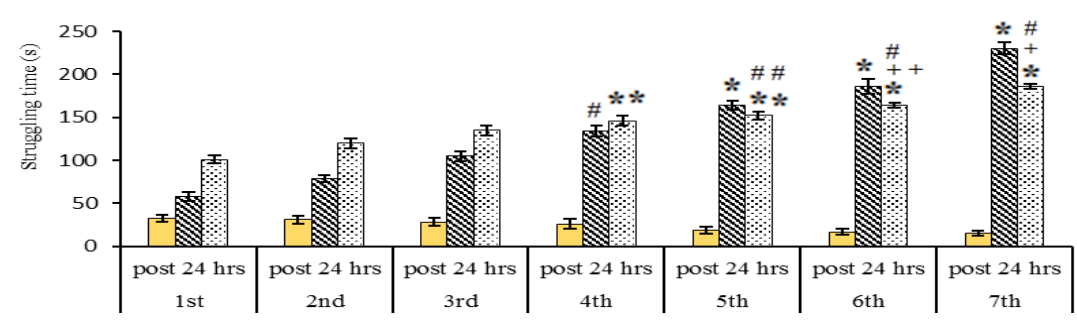

Fig. 4: Antidepressant responses of Agmatine and Mirtazapine in Forced swim Test (struggling time) 
Values are means + SD (n=6) as administered post 24 hours of drug administration. Significant differences by Newman-Keul's test: groups that differ significantly from respective saline treated controls $* \mathrm{p}<0.01, * * \mathrm{p}<0.05$; similar drug treated groups that significantly differ from $1^{\text {st }}$ administration $+p<0.01,++p<0.05$;

$\# \mathrm{p}<0.01$, \#\#p<0.05 from similarly administered drug of unstressed to stressed group on same day following three way ANOVA (repeated measure design).

\section{口Saline \$Agmatine 巴Mirtazapine}
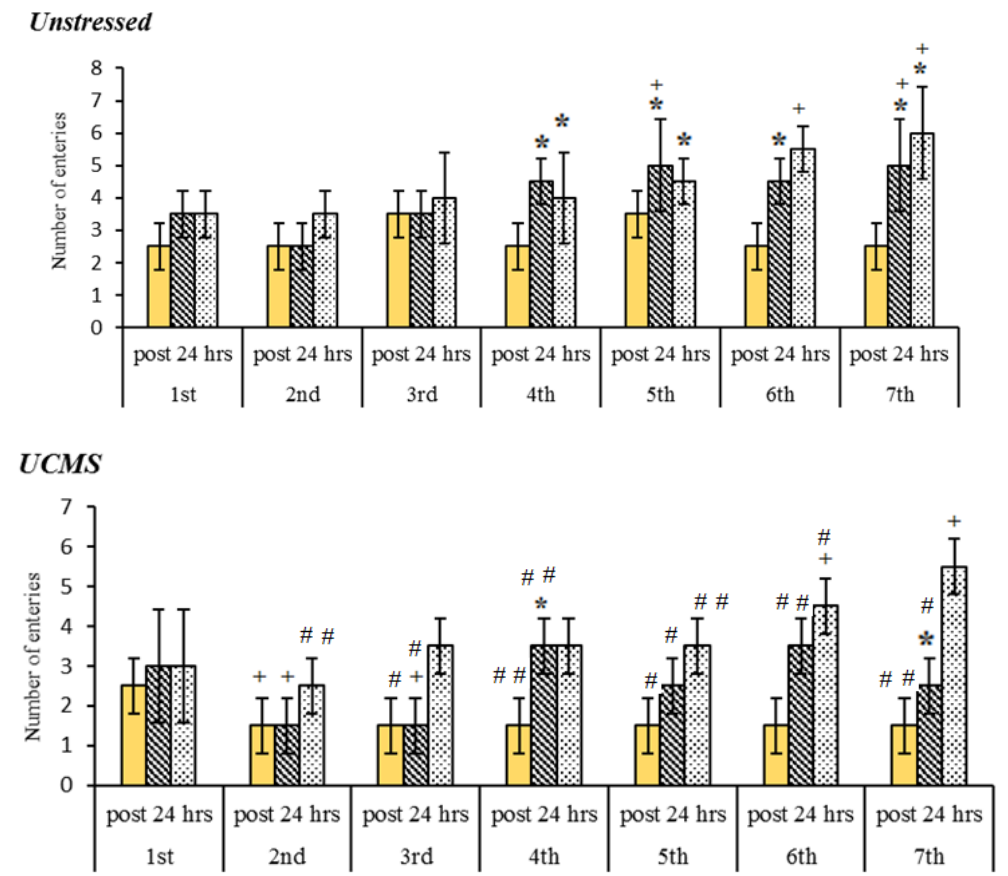

Fig. 5: Anxiolytic and Antidepressant Responses of Agmatine and Mirtazapine in Elevated Plus Maze (Entries in open arms)

Values are means + SD $(n=6)$ as administered post 24 hours of drug administration. Significant differences by Newman-Keul's test: *groups that differ significantly from respective saline treated controls $<p$ $0.01 ;+$ similar drug treated groups that significantly differ from $1^{\text {st }}$ administration $\mathrm{p}<0.01$;

$\# p<0.01, \# \# p<0.05$ from similarly administered drug of unstressed to stressed group on same day following three way ANOVA (repeated measure design).

Anxiolytic and Antidepressant Responses of Agmatine and Mirtazapine in Elevated Plus Maze (Entries in open arms)

Fig. 6 explained the frequency of entries of unstressed and stressed rats exposed to agmatine and mirtazapine in elevated plus maze. Results given by both the drugs and controls were assessed by III way ANOVA (repeated measure designs) that determined the significant effects of days $(F(6,33)=4.743$ $\mathrm{p}<0.05)$, drugs $(\mathrm{F}(1,33)=415.677 \mathrm{p}<0.05)$, stress $(\mathrm{F}$ $(1,33)=226.388 \mathrm{p}<0.10)$ and the interaction between

days, drugs and stress $(\mathrm{F}(6,33)=15.806 \mathrm{p}<0.01)$. Newman keul's post hoc analysis described the significant effects of agmatine in unstressed after $4^{\text {th }}$, $5^{\text {th }}, 6^{\text {th }}$, and $7^{\text {th }}(\mathrm{p}<0.01)$ and after $4^{\text {th }}$ and $7^{\text {th }}(p<0.01)$ drug administration in stressed group while mirtazapine a day after $4^{\text {th }}, 5^{\text {th }}, 7^{\text {th }}(\mathrm{p}<0.01)$ treatment improved entries occurrence in open arms of unstressed rats in contrast of their saline controls. Stress decreased arrival of saline controls significantly in open arms post 24 hours of $2^{\text {nd }}(p<0.01)$ administration whereas, agmatine increased entries after $5^{\text {th }}$ and $7^{\text {th }}(p<0.01)$ treatment in unstressed and decreased after $2^{\text {nd }}$ and $3^{\text {rd }}(p<0.01)$ administration on the other hand mirtazapine effected arrival of rats in open arms after $6^{\text {th }}$ and $7^{\text {th }}(\mathrm{p}<0.01)$ in both unstressed and stressed groups from first administration of all drugs separately. Stressed controls entered less in open arms after $3^{\text {rd }}, 5^{\text {th }}(\mathrm{p}<0.01)$ and $4^{\text {th }}$, $7^{\text {th }}(\mathrm{p}<0.05)$ treatment while stressed rats treated with agmatine entered less after $3^{\text {rd }}, 5^{\text {th }}, 7^{\text {th }}(\mathrm{p}<0.01)$ and $4^{\text {th }}$ and $6^{\text {th }}(\mathrm{p}<0.05)$ administration. Additionally, after $2^{\text {nd }}$ and $5^{\text {th }}(\mathrm{p}<0.05)$ and $6^{\text {th }} \quad(\mathrm{p}<0.01)$ treatment of mirtazapine, stress exposed rats entered significantly less in open arms in contrast to their unstressed rats. 
口Saline \$Agmatine వMirtazapine

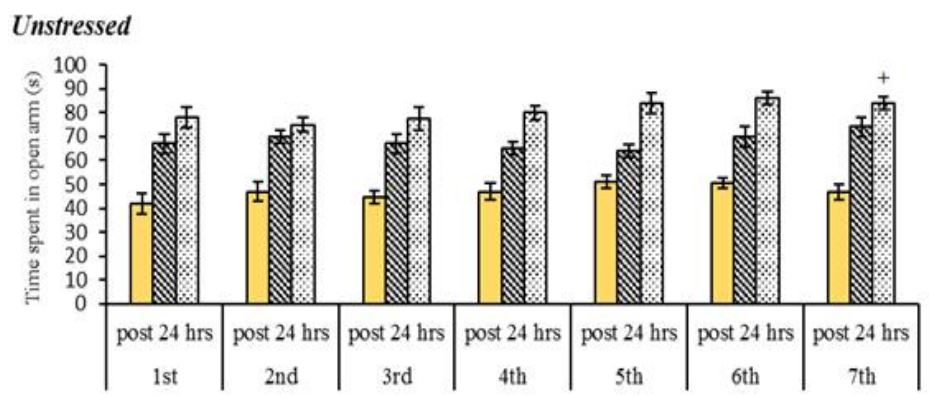

\section{UCMS}

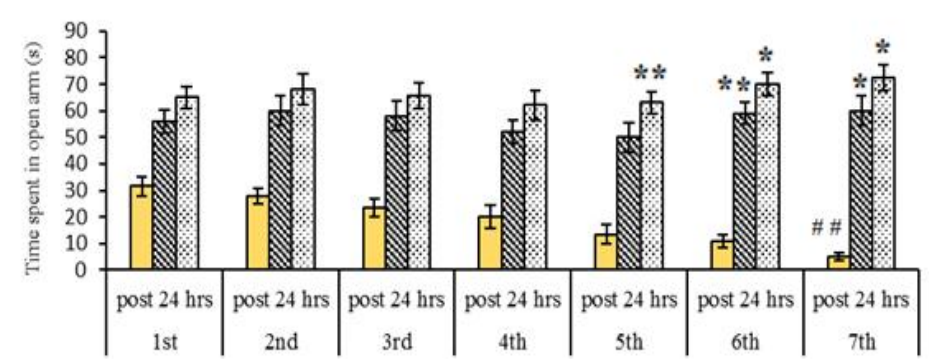

Fig. 6: Anxiolytic and Antidepressant Responses of Agmatine and Mirtazapine in Elevated Plus Maze (Time spent in open arms)

Values are means $+\mathrm{SD}(\mathrm{n}=6)$ as administered post 24 hours of drug administration. Significant differences by Newman-Keul's test: groups that differ significantly from respective saline treated controls $* \mathrm{p}<0.01$, $* * \mathrm{p}<0.05 ;+$ similar drug treated groups that significantly differ from $1^{\text {st }}$ administration $\mathrm{p}<0.01$;

$\# \mathrm{p}<0.01, \# \# \mathrm{p}<0.05$ from similarly administered drug of unstressed to stressed group on same day following three way ANOVA (repeated measure design).

Anxiolytic and Antidepressant Responses of Agmatine and Mirtazapine in Elevated Plus Maze (Time spent in open arms)

Time spent in open arms of elevated plus maze resulted by repeated administration of agmatine and mirtazapine in unstressed and unstressed groups of rats are explained in figure 04. All the data obtained was analyzed by III way ANOVA (repeated measure design) that demonstrated the effects of days $(\mathrm{F}(6,33)=$ $14.054 \mathrm{p}<0.01)$, drugs $(\mathrm{F}(1,33)=96.164 \mathrm{p}<0.1)$, and interaction of days, drugs and stress to be significant while non-significant effects of stress $(\mathrm{F}(1,33)=23.111)$ were observed. Newman Keul's test post-hoc analysis explained that agmatine increased the duration spent in open arms of EPM after $6^{\text {th }}(\mathrm{p}<0.05)$ and $7^{\text {th }} \quad(\mathrm{p}<0.01)$ administration and mirtazapine after $5^{\text {th }} \quad(\mathrm{p}<0.05)$ and $6^{\text {th }}, 7^{\text {th }} \quad(\mathrm{p}<0.01)$ treatment significantly in stressed rats when both groups of drugs compared from saline controls. Mirtazapine improved duration spent in open arms on $7^{\text {th }} \quad(p<0.01)$ administration from first treatment of mirtazapine dose in unstressed rats. Furthermore, Stress decreased time spent in open arms in saline controls after $7^{\text {th }}(p<0.05)$ day significantly.

\section{Discussion}

The present study was designed to determine the antidepressant and anxiolytic activity of agmatine particularly at the selected dose of $100 \mathrm{mg} / \mathrm{Kg}$ in chronic unpredictable mild stress induced depressive like behaviors and it's comparison with $30 \mathrm{mg} / \mathrm{kg} /$ day mirtazapine administration. Katz and coworkers initially originate the chronic mild stress model (CMS) consisted the etiology of depression (Katz, 1981) (Katz and Sibel, 1982). The classic model involves various mild stresses repetitive experiences during a specific time period that results it in extensive conventional model of depression (Krishnan and Nestler, 2011). Various studies support and recommend CUMS model of depression that it causes alternation in biochemical and behavioral aspects of animals and produces symptoms resemble to clinical depression (Luo et al., 2008).The behavioral paradigms used and results obtained in this particular study expressed the anhedonic, anxiogenic and depressive consequences produced by chronic mild stress. The protocol 
was consisted of paired stressors in which one is physical stress accompanied with a psychological mild distress. The protocol was designed in order to recognize the unrevealed impacts of dual stresses on rats and attenuation by agmatine administration.

Light/dark test paradigm is established on the natural behaviors of mice that include aversion of intensely lightened area and exploration in novel environment (Crawley, 1985). The selected two perimeters for light/dark transition tests were frequency of entries and spent time by the animal in lit box during 5 minutes testing session. The results revealed that 4 weeks administration of both agmatine (neuromodulator/neurotransmitter) and mirtazapine (noradrenergic and specific serotonergic antidepressant (NaSSA) produced anxiolytic and antidepressants effects in contrast to saline controls presented in figure 01 and 02 . Saline treated rats which were exposed to stress displayed significant reduction in entries and time spent in open arms. Stress leads to anxiety and depression which assessed in light/dark paradigm in rodents. Light/dark transition test extensively used to determine anxiety in animals (Crawley, 2000). Agmatine produces anxiolytic and antidepressant effects in stressed exposed rats when compared to saline controls. After $28^{\text {th }}$ administration, agmatine significantly increased arrival and duration that rats spent in light box in unstressed groups whereas CMS caused anxiogenic and depressive like behaviors that was improved by agmatine is illustrated in present study. Mirtazapine is a well-known antidepressant and was used to reduce depressive like behaviors in rodents in this experimental evaluation. When administered to unstressed and stressed rats, mirtazapine enhanced rat's activity in light/dark transition test. Post 24 hours of $28^{\text {th }}$ day of mirtazapine administration, undressed rats increased time spent and entries significantly whereas, stressed exposure affected both entries and time spent in light box. Mirtazapine improved activity compared to saline and agmatine treated rats. The light/dark test conventionally used to assess behaviors in animals treated with antidepressant and anxiolytic drug (Crawley, 1985).

Chronic mild stress exposed control group displayed decrease in mobility determined the depressive performance in forced swim test apparatus. Studies suggested that rats exposed to chronic mild stress displayed increased immobility and despair in forced swim test (Dalla et al., 2005) (Kompagne et al., 2008). Present study demonstrated the decrease in mobility and struggling as the consequence of CMS in saline controls whereas the rats which were remained unstressed persisted the struggling duration when forced to swim in water at room temperature. Agmatine efficiently increased the struggling ability in unstressed rats comparatively to saline controls whereas, CMS induced despair and melancholy worsen the mobility in rats that was improved by administration of agmatine significantly in four weeks duration. Mirtazapine on the other hand initiated greater mobility time and lessen the despair in unstressed and stressed exposed rats when compared to saline controls. Forced swim test is a paradigm used to evaluate the proficiency and effectiveness of antidepressants and validate the effects of several behavioral and psychological influences in preclinical research (Petit-Demouliere et al., 2005) (Porsolt et al., 1978, Mineur et al., 2006, Millstein et al., 2007). The test is known to interpret a condition in which despair behavior is induced in animal caused hopelessness (Porsolt et al., 1977).

Elevated plus maze is extensively used as a validity model for anxiolytic drugs screening (Rodgers and Dalvi, 1997, Mechiel Korte and De Boer, 2003, Crawley, 2007). The perimeters which are entries in open arms and time spent are assessed in which anxiolytic drugs increase and anxiogenic drugs decreased the activity in elevated plus maze test. Total score is the index of major anxiety in animals evaluated in EPM paradigm (Rodgers and Dalvi, 1997, Mechiel Korte and De Boer, 2003).

The particular study conducted to reveal the effects and impacts of CMS that produce depressive and anxiogenic behaviors in rats. Both stressed and unstressed groups of saline controls were assessed in elevated plus maze apparatus and obtained results determined the less entries and minimal time spent of stressed group of rats in open arms whereas, rats which were kept at normal environmental conditions and administered with saline only illustrated consistent activity in EPM paradigm. Agmatine on the other hand improved the frequency of entrance and time spent of rats that were not exposed to stress. Figure 05 and 06 explained the anxiogenic and anxiolytic efficacy of agmatine in animals acquainted with chronic unpredictable stresses. Stress that leads to anxiety and depression effected the activity in stressed group of rats when compared to saline stressed controls however simultaneous treatment with agmatine moderated the effects of stress and improved the performance of stressed rats. Furthermore investigations with mirtazapine revealed the anxiolytic effects of particular antidepressant of (NaSSA) group which shown the maximum 
number of entries and time period spent of unstressed and stressed exposed rats in open arms during 5 minutes test session. CMS influenced animals demonstrated the improved arrivals and consumed time in open arms as a result of the administration of both agmatine and mirtazapine at particular dose of $(100 \mathrm{mg} / \mathrm{kg})$ and $(30 \mathrm{mg} / \mathrm{Kg})$ respectively.

\section{Conclusion}

In conclusion, repetitive administration of agmatine attenuated the distress caused by chronic mild stress paradigm however this effect was developed after chronic treatment compared to conventional antidepressant management such as mirtazapine. Moreover, Agmatine and Mirtazapine are comparable to each other and further evaluation should be carried out before our results and outcomes become an approximate to depression therapy.

\section{References}

1. Berton O, Nestler EJ. New approaches to antidepressant drug discovery: beyond monoamines. Nat Rev Neurosci 2006;7:137-151.

2. Crawley, J. N. (2000). What's Wrong With My Mouse? Behavioral Phenotyping of Transgenic and Knockout Mice (John Wiley \& Sons, New York).

3. Crawley, J. N. Exploratory behavior models of anxiety in mice. Neurosci Biobehav Rev 1985;9:37-44.

4. Dalla C., Antoniou K., Drossopoulou G., et al. Chronic mild stress impact: are females more vulnerable? Neurosci 2005;135(3):703-14.

5. Dazzi L, Ladu S, Spiga F, Vacca G, Rivano A, et al. Chronic treatment with imipramine or mirtazapine antagonizes stress- and FG7142-induced increase in cortical norepinephrine output in freely moving rats. Synapse 2002;43:70-77.

6. De Kloet E. R., Joëls M., Holsboer F. (2005). Stress and the brain: from adaptation to disease. Nature Reviews Neurosci 6(6):463-75.

7. Katz, R. J. Animal models and human depressive disorders. Neurosci Biobehav Rev 1981;5:231-46.

8. Katz, R. J. \& Sibel, M. (1982). Animal model of depression: tests of three structurally and pharmacologically novel antidepressant compounds. Pharmacol Biochem Behav 1982;16:973-77.

9. Krishnan, V. \& Nestler, E. J. Animal models of depression: molecular perspectives. Curr Top Behav Neurosci 2011;7:121-47.

10. Kompagne H., Bárdos G., Szénási G., Gacsályi I., Hársing L. G., Lévay G. Chronic mild stress generates clear depressive but ambiguous anxiety-like behaviour in rats. Behavioural Brain Res 2008;193(2):311-14.

11. Luo DD, An SC and Zhang X. Involvement of hippocampal serotonin and neuropeptide $\mathrm{Y}$ in depression induced by chronic unpredicted mild stress. Brain Res Bull 2008;77:8-12.

12. Maes M. Evidence for an immune response in major depression: a review and hypothesis. Progress in NeuroPsychopharmacology and Biological Psychiatry; 1995;19(1):11-38.

13. Maes M. The cytokine hypothesis of depression: inflammation, oxidative \& nitrosative stress (IO\&NS) and leaky gut as new targets for adjunctive treatments in depression. Neuroendocrinol Letters 2008;29(3):287-91.

14. Maes M., Fišar Z., Medina M., Scapagnini G., Nowak G., Berk M. New drug targets in depression: inflammatory, cell-mediated immune, oxidative and nitrosative stress, mitochondrial, antioxidant, and neuroprogressive pathways. And new drug candidates-Nrf2 activators and GSK-3 inhibitors. Inflammopharmacol 2012;20(3):12750.

15. Matthews K. A., Gump B. B., Owens J. F. Chronic stress influences cardiovascular and neuroendocrine responses during acute stress and recovery, especially in men. Health Psychol 2001;20(6):403-10.

16. Mechiel Korte, S. \& De Boer, SF. A robust animal model of state anxiety: fear-potentiated behaviour in the elevated plus-maze. Eur J Phamacol 2003;463:163-75.

17. Miller D. B., O'Callaghan J. P. (2002). Neuroendocrine aspects of the response to stress. Metabolism: Clin Experiment 2002;51(6):5-10.

18. Millstein, R.A. \& Holmes, A. Effects of repeated maternal separation on anxiety- and depression-related phenotypes in different mouse strains. Neurosci Biobehavioral Rev 2007;31:3-17.

19. Mineur, Y.S., Belzung, C., \& Crusio, W.E. Effects of unpredictable chronic mild stress on anxiety and depression-like behavior in mice. Behav Brain Res 2006;175:43-50.

20. Monleon S., Parra A., Simon V. M., Brain P. F., D'Aquila P., Willner P. Attenuation of sucrose consumption in mice by chronic mild stress and its restoration by imipramine. Psychopharmacology; 1995;117(4):453-57.

21. Otake K, Ruggiero DA, Regunathan S, Wang H, Milner TA, Reis DJ. Regional localization of agmatine in the rat brain: an immunocyto-chemical study. Brain Res 1998;787:1-14.

22. Papp M., Willner P., Muscat R. An animal model of anhedonia: attenuation of sucrose consumption and place preference conditioning by chronic unpredictable mild stress. Psychopharmacology; 1991;104(2):255-59.

23. Pellow S, File S. Anxiolytic and anxiogenic drug effects on exploratory activity in an elevated plus-maze: a novel test of anxiety in the rat. Pharmacol Biochem Behav 1986;24:526-30.

24. Pellow S, Chopin P, File SE, Briley M. Validation of open: closed arm entries in an elevated plus-maze as a measure of anxiety in the rat. J Neurosci Method 1985;14:149-67.

25. Petit-Demouliere, B., Chenu, F., \& Bourin, M. Forced swimming test in mice: a review of antidepressant activity. Psychopharmacology. (Berl); 2005;177:245-55.

26. Porsolt, R.D., Bertin, A., \& Jalfre, M. (1978). "Behavioural despair" in rats and mice: strain differences and the effects of imipramine. Eur J Pharmacol 1978;51:291-94.

27. Porsolt, R.D., Bertin, A., \& Jalfre, M. Behavioral despair in mice: a primary screening test for antidepressants. Arch Int Pharmacodyn Ther 1977;229:327-36.

28. Rauggi R, Cassanelli A, Raone A, Tagliamonte A, Gambarana C. Study of mirtazapine antidepressant effects in rats. Int J Neuropsychopharmacol 2005;8:36979.

29. Reis DJ, Regunathan S. Agmatine: an endogenous ligand at imidazoline receptors may be a novel neurotransmitter in brain. J Auton Nerv Syst 1998;72:80-5.

30. Reis DJ, Regunathan S. Agmatine: an endogenous ligand at imidazoline receptors is a novel neurotransmitter. Ann N Y Acad Sci 1999;881:65-80. 
31. Reis DJ, Regunathan S. Is agmatine a novel neurotransmitter in brain? Trends Pharmacol Sci 2000;21:187-93.

32. Rodgers, RJ. \& Dalvi, A. Anxiety, defense and the elevated plus-maze. Neurosci Behav Rev 1997;21:801-10.

33. Sastre M, Regunathan S, Reis DJ. Uptake of agmatine into rat brain synaptosomes: possible role of cation channels. J Neurochem 1997;69:2421-26.

34. Shopsin B. The clinical antidepressant effect of exogenous agmatine is not reversed by parachlorophenylalanine: a pilot study. Acta Neuropsych 2013;25:113-18.

35. Siegrist J. Chronic psychosocial stress at work and risk of depression: evidence from prospective studies. Eur Arch Psychiatry Clin Neurosci 2008;258(5):115-19.

36. Stetler C., Miller G. E. (2011). Depression and hypothalamic-pituitary-adrenal activation: a quantitative summary of four decades of research. Psychosomatic Med 2011;73(2):114-26.

37. Tabor CW, Tabor H. Polyamines. Ann Rev Biochem 1984;53:749-90.

38. Willner P., Towell A., Sampson D., Sophokleous S., Muscat R. (1987). Reduction of sucrose preference by chronic unpredictable mild stress, and its restoration by a tricyclic antidepressant. Psychopharmacol 1987;93(3):358-64.
39. Willner P., Towell A., Sampson D., Sophokleous S., Muscat R. Reduction of sucrose preference by chronic unpredictable mild stress, and its restoration by a tricyclic antidepressant. Psychopharmacol 1987;93(3):358-64.

40. Willner P., Muscat R., Papp M. Chronic mild stressinduced anhedonia: a realistic animal model of depression. Neurosci Biobehavioral Rev 1992;16(4):52534.

41. Willner P. Chronic mild stress (CMS) revisited: consistency and behavioural-neurobiological concordance in the effects of CMS. Neuropsychobiol 52(2):90-110.

42. Zomkowski ADE, Hammes L, Lin J, Calixto JB, Santos ARS, Rodrigues ALS. Agmatine produces antidepressant-like effects in two models of depression in mice. Neuroreport 2002;13:387-91.

43. Zomkowski ADE, Rosa AO, Lin J, Santos ARS, Calixto $\mathrm{JB}$, Rodrigues ALS. Evidence for serotonin receptor subtypes involvement in agmatine antidepressant likeeffect in the mouse forced swimming test. Brain Res 2004;10(23):253-63.

44. Zomkowski ADE, Santos ARS, Rodrigues ALS. Evidence for the involvement of the opioid system in the agmatine antidepressant-like effect in the forced swimming test. Neurosci Lett 2005;381:279-83. 